\title{
EDUCAÇÃO PROGRESSISTA E DIREITOS EDUCACIONAIS DE ADOLESCENTES E JOVENS EM CUMPRIMENTO DE MEDIDAS SOCIOEDUCATIVAS
}

\author{
Fabíola Mônica da Silva Gonçalves \\ Universidade Estadual da Paraíba (UEPB), Campina Grande, Paraíba, \\ Brasil
}

ResUmo: Este artigo tem como objetivos (I) identificar possíveis relações entre o ECA e o SINASE em termos das orientações legais sobre os direitos educacionais e as medidas socioeducativas para adolescentes e jovens brasileiros, e (II) aproximar o pensamento pedagógico de Paulo Freire acerca de uma educação emancipatória a contextos institucionais de ressocialização de adolescentes e jovens em conflito com a lei. Para tal, utilizaram-se os procedimentos técnicos da análise documental e levantamento bibliográfico (GIL, 2008). Como conclusão, observaram-se um descompasso entre os dispositivos legais analisados e a situação real das medidas socioeducativas e, ao mesmo tempo, como a pedagogia freiriana pode lançar luz para a busca de mudança desta realidade social desumana. (FREIRE, 2008; 2004; 2001, 1992).

Palavras-chave: Educação Progressista. ECA. SINASE. Medidas Socioeducativas.

INTRODUÇÃO

Esta produção é fruto da busca de possíveis relações entre o pensamento pedagógico de Paulo Freire e os direitos educacionais de adolescentes e jovens em cumprimento de medidas socioeducativas. Isso foi 
feito a partir da análise de documentos oficiais que regulamentam práticas educativas para esta população estudantil brasileira.

Tomaram-se como material para proceder com o cotejamento das orientações legais que dispõem sobre o cumprimento de medidas socioeducativas o Estatuto da Criança e do Adolescente (ECA) (BRASIL, 2015a) (Lei $\mathrm{n}^{\circ}$ 8.069/1990), o Sistema Nacional de Atendimento Socioeducativo (SINASE) (BRASIL, 2015b) (Lei n 12594/2012), o Plano Nacional de Atendimento Socioeducativo (BRASIL, 2013) e o Levantamento Anual do SINASE de 2013 (BRASIL, 2015c) a fim de verificar as proposições e os encaminhamentos postos na documentação em destaque.

Procura-se, por intermédio desta análise, responder aos questionamentos: Por que estudar e entender o ECA e o SINASE a partir do pensamento pedagógico de Paulo Freire? Quais são as contribuições da pedagogia progressista vislumbradas aqui acerca dos fenômenos educativos? E, aliada às questões anteriores, quais as conclusões a que se chegou ao final desta atividade investigativa?

Assim, têm-se como objetivos norteadores: (I) identificar possíveis relações entre o ECA (BRASIL, 2015a) e o SINASE (BRASIL, 2015b) em termos das orientações legais sobre os direitos educacionais e as medidas socioeducativas para adolescentes e jovens brasileiros, e (II) aproximar o pensamento pedagógico de Paulo Freire acerca de uma educação emancipatória a contextos institucionais de ressocialização de adolescentes e jovens em conflito com a lei.

Desta maneira, este artigo se constitui como resultante de uma pesquisa exploratória sobre a temática em relevo, e é composto por duas seções: a primeira, por meio da análise documental, expõe e discute os aspectos relacionados aos direitos educacionais e às medidas socioeducativas dispostas no ECA, no SINASE e em documentos complementares. Já na segunda seção, construída a partir da pesquisa bibliográfica, foram destacadas algumas categorias do pensamento pedagógico de Paulo Freire, interpretadas aqui como favorecedoras de uma praxiologia dialógica dos direitos educacionais de adolescentes e jovens que se encontram em cumprimento de medidas socioeducativas e privados de liberdade (GIL, 2008).

O QUE TRAZEM O ECA E O SINASE SOBRE OS DIREITOS EDUCACIONAIS E AS MEDIDAS SOCIOEDUCATIVAS?

O ECA (BRASIL, 2015a) traz, em sua extensão textual, um elenco de dispositivos legais que asseguram os direitos educacionais e as medidas 
socioeducativas. Nas disposições preliminares, declara o período etário das três categorias de sujeitos que são atendidos por esta legislação, a saber: (I) criança - até 12 anos incompletos; (II) adolescente, considerado entre 12-18 anos; e (III) jovens, em termos excepcionais, entre 18 e 21 anos de idade (artigo $2^{\circ}$; parágrafo único).

Contudo, este critério etário como elemento demarcador dos períodos do desenvolvimento humano, sobretudo na adolescência e na juventude, foco das considerações deste trabalho, é limitado e incompatível com as configurações psicossociais contemporâneas.

Francisco e Groppo (2016) destacam que a legislação engessa a adolescência ao aspecto cronológico e desconsidera as múltiplas relações que cada indivíduo estabelece com as dimensões tempo e sociedade, tal como foram configuradas as primeiras perspectivas sobre esta fase do desenvolvimento humano, marcadas por concepções naturalizantes, negando, com isto, a diversidade de elementos sócio-históricos que a constituem.

Estes autores trazem perspectivas atuais que dão ênfase aos processos sociais, educativos e culturais constitutivos da adolescência, concebida como uma fase temporal relativa, que varia de pessoa para pessoa, noção esta assumida neste trabalho. Desta forma, hoje em dia, as chances dos adolescentes serem atores do seu processo histórico são maiores, o que promove uma ampliação de possibilidades e perspectivas culturais e profissionais. (FERREIRA; FARIAS; SILVARES, 2010).

Já a noção sobre juventude, da mesma forma que a concepção de adolescência, é posicionada aqui como uma construção histórica, compreendida nas/pelas relações socioculturais, multideterminadas por complexos elementos desdobrados na temporalidade. No entanto, a juventude é marcada como processo de desenvolvimento sucessor da adolescência e antecessor da vida adulta; em síntese, como processo de transição do desenvolvimento integral do homem, mesmo que se tomem os processos de subjetivação como principais marcadores para se compreender o fenômeno da juventude. (MELUCCI, 1997; PERALVA, 1997; SPOSITO, 1997; FREITAS, 2005; DIAS, 2011; FRANCISCO \& GRUPPO, 2016).

Assim, neste trabalho, a educação é pensada como um dos direitos fundamentais assegurados pelo Estado aos seus cidadãos consoante com a Declaração Universal dos Direitos Humanos (ONU, 1948). E é no campo educacional que se destacaram aqui as regulamentações do ECA (BRASIL, 2015a) à população de adolescentes e jovens com histórico infrator.

Adolescentes e jovens em cumprimento de pena, conforme o estatuto, têm seu direito educacional assegurado expressamente do artigo 53 
ao 59. Sendo que o artigo 53 dispõe sobre o direito à educação pautado no acesso e permanência na escola pública nas proximidades de sua residência, no respeito por parte dos educadores, na contestação dos critérios avaliativos, na participação em entidades estudantis. Já, em termos do dever do estado para com esta população, estão postos no artigo 54 a obrigatoriedade da oferta em todos os seguimentos da educação básica do sistema público de ensino brasileiro, que compreende o atendimento em creche e pré-escola até o ensino médio, e dispõe inclusive sobre o atendimento de adolescentes e jovens fora da faixa-etária regular, com garantia de acesso para os que trabalham, com a oferta do ensino noturno, e, além do direito educacional, a participação em programas suplementares de material didático-escolar, transporte, alimentação e assistência à saúde.

Os artigos 55 e 56 tratam das incumbências da família e do Conselho Tutelar como instâncias sociais e institucionais que primam pelo cumprimento da frequência e da participação destes adolescentes e jovens na unidade escolar. Cabe à família matricular e acompanhar seus filhos, e ao Conselho Tutelar monitorar a frequência, a não justificativa das faltas e os fatores que provocam múltiplas repetências.

Do artigo 57 ao 59, verifica-se um conjunto de direitos educacionais da competência de cada ente federativo (Município, Estado e União) a fim de garantir a oferta e permanência de jovens e adolescentes infratores no sistema educacional público. Medidas estas voltadas para dimensões de gestão e organização da aprendizagem na unidade escolar ligadas ao currículo, à avaliação, ao calendário e às metodologias de ensino, passando por questões relacionadas aos valores culturais peculiares do contexto social desta população estudantil, até a disponibilidade de recursos por estes entes federativos para implementação de programas culturais, esportivos e de lazer voltados para a infância e juventude.

Adiante, o ECA (BRASIL, 2015a) dispõe sobre medidas socioeducativas no artigo 112, o qual explicita que a partir da ocorrência do ato infracional, cabe à autoridade judicial aplicar uma ou mais de uma das seis medidas alternativas, conforme o caso em análise, a saber: I - advertência; II - obrigação de reparar o dano; III - obrigação de serviços à comunidade; IV - liberdade assistida; V - inserção em regime de semiliberdade; e VI - internação em estabelecimento educacional (BRASIL, 2015a, p. 52). Este artigo ainda conta com mais um inciso e três parágrafos que não foram transcritos aqui em função de não serem alvo desta análise.

Com base nas orientações legais disposta no ECA (BRASIL, 2015a) acerca dos direitos educacionais e das medidas socioeducativas, vê-se 
que as proposições buscam a ressocialização e o resgate da cidadania de adolescentes e jovens infratores. No entanto, encontra-se expresso no Plano Nacional de Atendimento Socioeducativo (2013, p. 10), realizado por meio de muitos estudos e experiências neste campo, o reconhecimento de que "o sistema socioeducativo ainda não incorporou nem universalizou em sua prática todos os avanços consolidados na legislação".

Em consonância com a afirmação acima sobre o descompasso entre a dinâmica do sistema socioeducativo brasileiro e as proposições presentes na legislação nacional pertinente a esta temática, encontra-se o diagnóstico deste fenômeno no documento que descreve o levantamento anual do Sistema Nacional de Atendimento Socioeducativo (SINASE) de 2013. Este material apresenta dados das cinco regiões brasileiras com vistas a subsidiar a qualificação do sistema socioeducativo do país. Dentre os dados apresentados no levantamento do SINASE de 2013 (BRASIL, 2015c), destacam-se aqueles relacionados à medida socioeducativa VI do artigo 112 do ECA, que dispõe sobre a internação em estabelecimento educacional. Este documento informa o contingente de 23.066 adolescentes e jovens (12 a 21 anos) em restrição e privação de liberdade (internação, internação provisória e semiliberdade). Tal levantamento enfatizou ainda um aumento constante entre os anos de 2010 a 2013 para a modalidade socioeducativa de internação (64\%), e para a modalidade socioeducativa de internação provisória (23\%) (BRASIL, 2015c, p. 17). Dados estes que comprovam a ineficácia, ou não aplicabilidade significativa, em termos percentuais, das medidas socioeducativas reparadoras, como: advertência, obrigação de reparar o dano, prestação de serviços comunitários e liberdade assistida.

A criação do SINASE em 2006, sendo regulamentado como lei em 2012, aconteceu com o objetivo de assegurar os direitos dos adolescentes e jovens em cumprimento de medidas socioeducativas previstas no ECA (BRASIL, 2015a). Este dispositivo legal acentua o potencial da educação no processo de ressocialização por preconizar as ações educativas em regime de cumprimento aberto, pois proporcionam a inserção do jovem e do adolescente infrator nas redes de proteção, de convivência familiar e comunitária (SALUM, 2015).

Como se trata de uma ação complexa, privilegiaram-se para a abordagem as orientações dispostas no SINASE (BRASIL, 2015b) relacionadas à modalidade de cumprimento de pena em regime de reclusão, uma vez que esta população infratora tem crescido nos últimos anos, de acordo com os dados aqui apresentados. Desta maneira, no artigo 15 do documento são explicitados os requisitos específicos para inscrição de programas de 
regime de semiliberdade ou internação. Adiante, o artigo 35 dispõe sobre os princípios gerais da execução das medidas socioeducativas listadas em nove incisos, no entanto, ressaltam-se aqui a "prioridade a práticas ou medidas que sejam restaurativas e, sempre, que possível, atendam às necessidades das vítimas" (Inc. III); a "individualização, considerando-se idade, capacidades e circunstâncias pessoais do adolescente" (Inc. VI); a "mínima intervenção, restrita ao necessário para a realização dos objetivos da medida" (Inc. VII); e, por último, "não discriminação do adolescente, notadamente em razão da etnia, gênero, nacionalidade, classe social, orientação religiosa, política ou sexual, ou associação ou pertencimento a qualquer minoria ou status" (Inc. VIII) (BRASIL, 2015b, p. 164-165).

Os incisos descritos aqui evidenciam o cuidado com a integridade física, sociocultural e étnico-racial do adolescente e jovem em cumprimento de medidas socioeducativas, o que permite pensar que o SINASE (BRASIL, 2015b) preconiza uma prática educativa humanizadora na condução dos atos infracionais por sujeitos em processo de desenvolvimento psicossocial.

Já o artigo 48 elenca os direitos individuais de adolescentes submetidos ao cumprimento de medidas socioeducativas para que o programa de ressocialização transcorra com vistas a, de fato, proporcionar a recuperação da cidadania, com o retorno do convívio social em liberdade.

Por fim, o SINASE (BRASIL, 2015b) traz, do artigo 52 ao 59, as diretrizes para a materialização dos direitos educacionais dos adolescentes em cumprimento de medidas socioeducativas, por meio da organização de um Plano Individual de Atendimento (PIA). No caso daqueles que cumprem em regime de internação (artigo 55) - além de ser necessária a elaboração de um PIA em que estejam expressos: os resultados da avaliação interdisciplinar; os objetivos declarados pelo adolescente; a previsão das atividades de integração social e/ou capacitação profissional; atividades de integração e apoio à família; formas de participação da família para efetivo cumprimento individual; e as medidas específicas de atenção à sua saúde - acrescentam-se outros itens relevantes, como: a definição das atividades internas e externas, individuais ou coletivas das quais os adolescentes poderão participar e a fixação das metas para o alcance e desenvolvimento de atividades externas. Conforme prescrito neste documento, o prazo de conclusão do PIA para ingresso do adolescente no programa de atendimento é de 45 dias (artigo 56).

Sobre os pontos traçados pelo SINASE (BRASIL, 2015b) acerca dos direitos individuais e da integração do adolescente ao programa ressocializador, foram apresentadas no Plano Nacional de Atendimento Socioeducativo (2013) treze constatações que evidenciam a inaplicabilidade 
de suas diretrizes. No entanto, para efeito ilustrativo da contradição entre a prescrição e ação das medidas socioeducativas, serão apresentadas partes destas constatações:

Violações constantes aos direitos dos adolescentes; [...] Superlotação nas unidades socioeducativas; Inadequação de instalações físicas: condições insalubres e ausência de espaços físicos adequados para escolarização, lazer, profissionalização, saúde e outras políticas necessárias; [...] Implantação insuficiente ou uso inadequado do Plano Individual de Atendimento - PIA, comprometendo o projeto socioeducativo; Baixa efetividade na apuração e responsabilização dos agentes públicos nos casos de violação aos direitos dos adolescentes, ocorridas no interior das unidades de privação de liberdade; [...] Permanência dos adolescentes em unidades distantes do domicílio de seus responsáveis e de sua comunidade; [...] Desarticulação entre os executores das medidas socioeducativas de internação e em meio aberto (BRASIL, 2015b, p. 18-19).

No artigo 58 do mesmo documento, está disposto o processo de monitoramento do cumprimento do PIA pelo adolescente infrator com a reavaliação da medida por meio de relatório da equipe técnica. $\mathrm{E}$ o último ponto ressaltado aqui é o artigo 59, o qual resguarda os registros do plano de atendimento do adolescente em sigilo, com acesso restrito aos servidores do programa de atendimento, ao adolescente, aos pais ou responsáveis, bem como ao Ministério Público e ao defensor, com exceção de quebra de sigilo apenas para mandatos judiciais.

Conforme o Plano Nacional de Atendimento Socioeducativo (2013), em termos dos recursos humanos necessários para o desenvolvimento do programa de ressocialização, há instabilidade e obstáculos para a efetivação de um trabalho educativo humanizado com vistas à transformação da realidade sociocultural dos adolescentes em conflito com a lei, uma vez que apresenta, dentre um conjunto de problemas:

Quadro de pessoal do sistema socioeducativo pouco estruturado, insuficiente e incompleto para o atendimento da demanda, segundo diretrizes do SINASE; Remuneração incompatível com o trabalho especializado exigido; Alta rotatividade de pessoal, principalmente devido à carência de servidores efetivos, tanto nas unidades de meio fechado quanto nas unidades de meio aberto; Equipe técnica e de gestão com necessidade específica de qualificação e capacitação continuada; Formação fragmentada e desarticulada dos profissionais que atuam no Sistema; Fragilidade institucional da política: articulação incipiente entre os órgãos envolvidos na gestão, insuficiência de regulamentação e cofinanciamento; Carência de suporte em saúde mental para todos os operadores institucionais (BRASIL, 2013, p. 20). 
Com efeito, a partir do cotejamento realizado entre os documentos legais selecionados neste trabalho, é possível ver a distância que separa a prescrição da ação das medidas socioeducativas direcionadas para os adolescentes e jovens infratores. Essa disparidade acirra cada vez mais a marginalização social desta população que tem assegurados, tanto no ECA (BRASIL, 2015a) como no SINASE (BRASIL, 2015b), o acesso e permanência ao direito fundamental da educação como um instrumento social capaz de transformar a realidade cultural de sujeitos que se encontram em situação de restrição de liberdade.

Na perspectiva de uma educação humanizadora para jovens e adolescentes infratores, procedeu-se, a seguir, com uma análise transversal em parte da obra de Paulo Freire acerca da temática em relevo exposta a seguir.

COMO O PENSAMENTO DE PAULO FREIRE TRAZ LUZ AOS CONTEXTOS EDUCATIVOS DE RESSOCIALIZAÇÃO DE ADOLESCENTES E JOVENS INFRATORES?

Freire (1992) argumenta que subjetividade e objetividade são oposições sustentadas em uma prática libertadora humanizada, haja vista que a díade homem-mundo é constituída de maneira integrada, concebida como uma unidade dialética, pois "a liberdade, que é uma conquista, e não uma doação, exige permanente busca" (1992, p. 34). Por conseguinte, a realidade social, objetiva, que não existe de modo natural e espontâneo, mas como fruto da produção intencional dos homens, da mesma forma, não se transforma naturalmente. Se os homens são produtores da realidade, num exercício praxiológico, a mudança de realidades condicionadoras e repressoras só se conquista por meio de uma ação-reflexão social, cultural e histórica, produzida no bojo da atividade humana.

Têm-se, desta maneira, a objetividade prescrita socialmente para a educação da população adolescente e jovem infratora brasileira (por exemplo, o ECA e o SINASE) em documentos oficiais, e, por outro lado, porém indissociável, a subjetividade daqueles que serão submetidos ao cumprimento das medidas socioeducativas. Esta relação dialética é ponto plausível de múltiplas interpretações acerca de caminhos que gerem uma prática educativa humanizada com força transformadora.

No entanto, assumir uma visão freiriana de educação implica o desvelamento de práticas bancárias que se constituem em narrativas sobre o outro e não com o outro. Uma prescrição produzida por alguém ou grupo que propõe condutas para outro grupo ou pessoa executar, sem a devida vivência daquele contexto, está predisposta ao naufrágio. Falar de 
fome apresenta conotação profundamente distinta quando proveniente daqueles que falam sem nunca ter passado por ela, em relação àqueles que falam porque a sentem no dia a dia. Sendo assim, nesta dualidade entre narrador-observador e personagem real abre-se inevitavelmente um hiato, uma dicotomia dando empoderamento social e histórico ao grupo que "fala sobre" em detrimento do grupo que vive concretamente os condicionamentos existenciais que a fome produz.

Nesta linha de pensamento, voltando-se agora para a questão das medidas socioeducativas, o narrar a partir da prescrição legal sobre como conduzir práticas restauradoras para os jovens e adolescentes infratores certamente não levará a emancipação destas pessoas. Faz-se necessário vivenciar práticas educativas construídas em conjunto: narrador-observador e personagem. Com o despojar-se de concepções prévias, sendo a lei vista como opressora e os infratores vistos como oprimidos, e assumindo uma narrativa dialógica e horizontalizada, é possível conceber ambos como agentes engajados pela busca da mudança dos condicionantes sociais que determinam este estado de dominação e estagnação social, situação esta que favorece a permanência de processos desumanizantes e fatalistas. É o famoso "não tem jeito, só se resolve a problemática com a prisão!". No entanto, a criminalidade é factual, e reincidente na trajetória de vida dos adolescentes e jovens infratores, comprovando assim a ineficiência da medida socioeducativa de internação em detrimento da colaboração dos agentes envolvidos no processo educativo ressocializador.

A educação problematizadora parte dos elementos históricos e da historicidade dos homens. O trajeto que se efetiva na temporalidade afirma o inacabamento tanto do homem como da história, daí o porquê de a educação ser uma ação contínua em um dado contexto social e cultural, que para acontecer de forma exitosa carece da integração e colaboração de todos sujeitos que dela participam. (FREIRE, 1992).

Para Freire (2001) a educação articulada aos direitos humanos é insoluvelmente um direito fundamental, pois não é uma questão que se possa explicar pela tecnocracia e nem pela pedagogia em si mesma. A educação exige uma compreensão política substantiva. Desta maneira, a educação para os direitos humanos, na perspectiva da justiça, é uma ação motivada e intencionada a despertar os dominados para "a necessidade da briga, da organização, da mobilização crítica, justa, democrática, séria, rigorosa, disciplinada, sem manipulações, com vistas à reinvenção do mundo, à reinvenção do poder" (FREIRE, 2001, p. 99). 
Com efeito, esta concepção de educação postulada pelo pedagogo declara uma compreensão diferente de desenvolvimento humano, a qual conduz ao engajamento crescente e crítico dos grupos populares. Além disso, este posicionamento encontra-se alinhado com as concepções destacadas aqui sobre a constituição subjetiva de adolescência e juventude, que remete às ideias de transitividade e multideterminações sócio-históricas. O estudioso em questão ainda alerta que não se pode pensar que a educação em si é tão poderosa, ou seja, que apenas ela irá resolver os dilemas sociais e culturais que enfrentamos, seria ingenuidade de nossa parte pensar assim, por outro lado, ao mesmo tempo que a educação não pode tudo, o autor diz que ela pode alguma coisa. Cabe a nós descobrir os espaços para a ação, pois este é um processo de organização social constante. Tal qual explicita Freire (2001, p. 101), uma educação progressista tem que ser "corajosa, curiosa, despertadora da curiosidade, mantenedora da curiosidade".

Sendo assim, tratar de uma educação na perspectiva freiriana para enfrentar as condições sociais, históricas e culturais de adolescentes e jovens em situação de cumprimento de medidas socioeducativas exige uma ação política capaz de promover o engajamento contínuo junto com os beneficiados pela educação que se vivencia. Faz-se necessário que as pessoas se vejam inseridas e contempladas, se reconheçam como sujeitos do processo educativo e não como um objeto, ao qual será transferido o conhecimento. A significação por parte dos que vivem a prática educativa é um fator primordial para que esta se efetive como um direito fundamental, por ter sido uma conquista e não uma doação. Afinal, "a educação tem caráter permanente. Não há seres educados e não educados. Estamos todos nos educando. Existem graus de educação, mas estes não são absolutos." (FREIRE, 2008, p. 13).

Para Freire (2008), a estrutura social é construída na tensão entre a mudança e a estabilidade, entre o dinâmico e o estático. Assim, pensar a dialética mudança/estabilidade em uma estrutura social situada implica, necessariamente, analisar o agir do trabalhador social na realidade que o circunda, pois é preciso ter consciência de que somente se pode entender ou explicar a si mesmo como um ser de relação com esta realidade, visto que o seu agir é produzido em conjunto com os outros homens, os quais se encontram na mesma condição que ele, em permanente mudança e estabilidade, sendo imprescindível conhecer a realidade na qual atua com os outros homens.

Desta maneira, o trabalhador social não tem como ser neutro frente ao mundo, diante da desumanização ou humanização, plasmado na permanência do que já não representa a trilha percorrida pelo humano ou a mudança destes percursos. Segundo Freire (2008), ao optar pela mudança, o 
trabalhador social não manipula a realidade, não se opõe à liberdade, não se exime da comunicação, pelo contrário. Consoante com a posição de agente de transformação social, em qualquer momento histórico em se que esteja, viável ou não para mudança, cabe a ele atuar e refletir com os indivíduos com quem trabalha para conscientizarem-se mutuamente das reais dificuldades da sua sociedade.

Articulado ao processo de conscientização como mecanismo promotor de mudança social, Freire (2004) traz o compromisso ético do educador social com o reconhecimento e a assunção da identidade cultural de seus educandos. É um processo de escuta permanente por parte do educador social para a abertura à fala do outro, às diferenças do outro. No entanto, esta prática progressista de educação não implica na anulação das posições assumidas pelo educador social, pelo contrário, é escutando bem que a capacidade de se colocar diante das situações, de expor o seu ponto de vista, acontece por meio de um processo dialógico que recusa atos educativos pautados no autoritarismo, no apagamento da autonomia do sujeito no seu processo de desenvolvimento psicossocial.

Frente ao exposto, vislumbra-se o Plano Individual de Atendimento (PIA), recomendado no SINASE (BRASIL, 2015b), como um instrumento pedagógico com potencial para promoção de uma prática educativa emancipadora e progressista, uma vez que para sua construção faz-se necessário um trabalho em conjunto entre o educador social e o adolescente ou jovem engajado no programa de ressocialização. É uma atividade que se constitui a partir de uma realidade social objetiva, mas que prima pela escuta da subjetividade daquele que irá cumprir o programa socioeducativo - o que de fato pode ser praticado em função dos condicionamentos sociais, culturais e históricos constitutivos da realidade que envolve os agentes da prática educativa, no caso os reeducandos e o educador social.

No entanto, como traz o Plano Nacional de Atendimento Socioeducativo (2013), há grandes distorções na realidade dos programas educacionais promotores de ressocialização de adolescentes e jovens infratores que impedem a condução das atividades nas instituições prisionais voltadas para a garantia dos direitos humanos. A formação dos trabalhadores sociais que atuam nestas instituições é deficitária e fragmentada, segundo o diagnóstico expresso neste documento, comprometendo a ação pedagógica destes profissionais, pautada na dimensão dialógica com amplo processo de conscientização para mudança social. A rotatividade dos profissionais que atuam neste segmento também colabora para um programa socioeducativo fragmentado e com baixa eficiência de resolutividade, ausente de uma 
sistemática ação-reflexão permanente, que favoreça mudanças sociais consistentes e consoante com a dinâmica vivenciada no cotidiano pelos agentes engajados, no caso, ressocializandos e trabalhadores sociais.

Outro ponto que merece destaque está relacionado à constante violação dos direitos dos reeducandos infratores. A falta de ética, do respeito aos direitos fundamentais destas pessoas, reforça a manutenção de um estado de vulnerabilidade social que cresce em larga escala. A marginalização se enraíza cada vez mais, dando mais espaço às forças políticas reacionárias que agem com violência em favor da "ordem e do progresso social", ao passo que uma educação progressista, com vistas à integração social de pessoas em conflito com a lei, encontra fortes mecanismos de resistência para a mudança desta realidade social.

A infraestrutura das instituições socioeducativas é um condicionante social que imprime a perpetuação das práticas educativas que não avançam na direção da autonomia dos reenducandos que cumprem medidas socioeducativas em regime fechado, dada a superlotação e a precarização dos espaços físicos para o desenvolvimento de atividades integradas entre a educação, o lazer, a saúde e a cidadania em plenitude. Além disso, falta um programa ressocializador mais eficaz na integração e participação das famílias destes jovens e adolescentes, agravando ainda mais os fatores psicossociais que desencadeiam e reforçam a exclusão destas pessoas da sociedade em que vivem.

\section{CONCLUSÃO}

Como ponto de partida para este trabalho, buscou-se identificar possíveis relações entre o ECA (BRASIL, 2015a) e o SINASE (BRASIL, 2015b) como dispositivos legais que apontam diretrizes para a garantia dos direitos educacionais quanto ao cumprimento de medidas socioeducativas por adolescentes e jovens infratores. Assim, como primeira relação, pode-se constatar que estes dois documentos são complementares entre si, sendo o ECA a legislação pioneira e o SINASE criado como um mecanismo de ampliação dos direitos fundamentais do ECA.

No entanto, como visto no Levantamento anual do SINASE (BRASIL, 2015c) e no Plano Nacional de Atendimento Socioeducativo (BRASIL, 2013), entre a prescrição legal expressa no ECA e no SINASE há uma discrepância significativa, evidenciando um longo caminho a ser percorrido. Mesmo depois de quase três décadas de a legislação do ECA ter sido sancionada, a mudança da realidade social com vistas à melhoria da qualidade de vida psicossocial da população estudantil infratora ainda é incipiente e com baixa 
representatividade, comprovando profundas distorções que carecem de um trabalho focado na superação da realidade social necrófila instaurada no contexto institucional ressocializador (FREIRE, 1992).

Com efeito, o pensamento pedagógico de Paulo Freire funcionou aqui como uma leitura reflexiva do que está prescrito na legislação destacada e quais as possibilidades de mudança social que uma prática educativa progressista pode promover nas instituições socioeducativas que trabalham para ressocialização de adolescentes e jovens infratores. Como síntese desta aproximação teórica e metodológica, tem-se no epicentro deste processo educativo um trabalho pautado na dialogicidade permanente entre todos os agentes sociais envolvidos. Trabalho esse que favoreça, sobretudo, o reeducando para o ato de reconhecer-se, de conscientizar-se como sujeito que produz conhecimento com potencial de intervir no mundo, transformandose em agente de mudança social engajado na reciprocidade e autenticidade com os trabalhadores sociais em direção a uma prática cultural libertadora.

Desta maneira, para construção de uma prática educativa emancipadora com adolescentes e jovens em cumprimento de medidas socioeducativas, com vistas à superação da dissonância entre o prescrito na legislação aqui analisada e a realidade na condução de um trabalho focalizado na cidadania destas pessoas, no interior das instituições ressocializadoras, fica evidente que no campo da pesquisa muito se tem a realizar.

Neste sentido, faz-se necessário ampliar e aprofundar pesquisas que se ocupem em circunscrever os aspectos envolvidos na relação entre adolescentes e jovens e as medidas socioeducativas, a saber: (I) investigar de que maneira a educação escolar vivenciada no interior das instituições ressocializadoras favorece ou não o processo de emancipação e construção da cidadania de adolescentes e jovens em cumprimento de medidas socioeducativas em regime fechado; (II) averiguar como tem ocorrido a formação continuada dos profissionais envolvidos na elaboração e no acompanhamento do Plano Individual de Atendimento (PIA) com vistas a serem de fato mediadores do processo de construção da cidadania das pessoas beneficiadas pelo programa de ressocialização; (III) conhecer e analisar até que ponto as atividades ressocializadoras vivenciadas por adolescentes e jovens privados de liberdade propiciam espaços para reflexão e mudança social; e (IV) compreender como são construídas as relações interpessoais entre os profissionais responsáveis, e os adolescentes e jovens privados de liberdade em cumprimento de medidas socioeducativas. 
PROGRESSIVE EDUCATION AND EDUCATIONAL RIGHTS OF ADOLESCENTS AND YOUNG PEOPLE IN COMPLIANCE WITH SOCIO-EDUCATIONAL MEASURES

ABSTRACT:The purpose of this study is to (i) identify possible relationships between ECA and SINASE in terms of legal guidelines on educational rights and socio-educational measures for Brazilian adolescents and young people, and (ii) to approach Paulo Freire's pedagogical thinking about an emancipatory education in institutional contexts of resocialization for adolescents and young people in conflict with the law. For this, the technical procedures of documentary analysis and bibliographic survey (GIL, 2008) were used. As a conclusion, there was a mismatch between the legal provisions analyzed and the actual situation of socio-educational measures and, at the same time, it was observed how Freire's pedagogy can shed light to the search for change in this inhuman social reality. (FREIRE, 2008; 2004; 2001; 1992).

KEYwords: Progressive Education. ECA. SINASE. Socio-educational Measures.

\section{EDUCACIÓN PROGRESISTA Y DERECHOS EDUCACIONALES DE ADOLESCENTES Y JÓVENES QUE CUMPLEN MEDIDAS SOCIOEDUCATIVAS}

RESUMEN: Los objetivos de este estudio son (i) identificar posibles relaciones entre el ECA y el SINASE, observándolos como orientaciones legales relacionadas a los derechos educacionales y a las medidas socioeducativas para adolescentes y jóvenes brasileños, y; (ii) aproximar el pensamiento pedagógico de Paulo Freire, sobre la educación emancipadora, a contextos institucionales de resocialización para adolescentes y jóvenes en conflictos con la ley. Para eso, se utilizaron los procedimientos técnicos del análisis documental y la revisión bibliográfica (GIL, 2008). Se llegó a la conclusión de que existe un descompás entre los dispositivos legales analizados y la situación real de las medidas socioeducativas y, al mismo tiempo, también se observó que la pedagogía de Freire puede lanzar luz para la búsqueda de cambios de esa realidad social inhumana. (FREIRE, 2008; 2004; 2001; 1992).

Palabras Clave: Educación Progresista. ECA. SINASE. Medidas Socioeducativas.

\section{REFERÊNCIAS}

BRASIL. Plano nacional de atendimento socieducativo: diretrizes e eixos operativos para o SINASE. Brasília: Secretaria de Direitos Humanos da Presidência da República, 2013. $39 \mathrm{p}$.

. Lei no 8069, de 13 de julho de 1990. Institui o Estatuto da Criança e do Adolescente. In: . Estatuto da Criança e do Adolescente: Lei no 8069, de 13 de julho de 1990. Recife: CEDCA, 2015a. p. 150-183. 
. Lei $\mathrm{n}^{\circ} 12.594$, de 18 de janeiro de 2012. Institui o Sistema Nacional de Atendimento Socioeducativo. In:___. Estatuto da Criança e do Adolescente: Lei no 8069, de 13 de julho de 1990. Recife: CEDCA, 2015b. p. 150-183.

. Levantamento anual SINASE 2013. Brasília: Secretaria de Direitos Humanos da Presidência da República, 2015c.

DIAS, A. F. O jovem autor de ato infracional e a educação escolar: significados, desafios e caminhos para a permanência na escola. 2011. 169 f. Dissertação (Mestrado em Educação) Programa de Pós-Graduação em Educação da Universidade Federal de São Carlos, São Carlos, SP, 2011.

FERREIRA, T. H. S.; FARIAS, M. A.; SILVARES, E. F. M. Adolescência através dos séculos. Psicologia: teoria e prática, Brasília, v. 26, n. 2, p. 227-234, 2010.

FRANCISCO, J. C.; GROPPO, L. A. Adolescência(s) e juventude(s): considerações a partir de uma coexistência legal. Crítica Educativa, Sorocaba, v. 2, n. 2, p. 275-294, jul./dez. 2016.

FREIRE, P. Educação e mudança. 31. ed. São Paulo: Paz e Terra, 2008.

Pedagogia da autonomia: os saberes necessários à prática educativa. 29a edição. São Paulo: Paz e Terra, 2004.

. Pedagogia dos mundos possíveis. São Paulo: UNESP, 2001.

Pedagogia do oprimido. 20. ed. Rio de Janeiro: Paz e Terra, 1992.

FREITAS, M. V. (Org.). Juventude e adolescência no Brasil: referências conceituais. São Paulo: Ação Educativa, 2005.

GIL, A. C. Métodos e técnicas de pesquisa social. 6. ed. São Paulo: Atlas, 2008.

MELUCCl, A. Juventude, tempo e movimentos sociais. Revista Brasileira de Educação, Rio de Janeiro, no. 5-6, p. 5-14, 1997.

ONU. Organização das Nações Unidas. Declaração Universal dos Direitos Humanos. 1948. Disponível em: <http://www.direitoshumanos.usp.br/index.php/ Declara\%C3\%A7\%C3\%A3o-Universal-dos-Direitos-Humanos/declaracao-universal-dos-direitos-humanos.html>. Acesso em: 30 out. 2016.

PERALVA, A. O jovem como modelo cultura. Revista Brasileira de Educação, Rio de Janeiro, n. 5-6, p. 15-24, 1997.

SALUM, M. J. G. O adolescente, as medidas socioeducativas e a responsabilização progressiva: 0 ato infracional e suas implicações objetivas e subjetivas. In: CONSELHO FEDERAL DE PSICOLOGIA; CONSELHO NACIONAL DOS DIREITOS DA CRIANÇA E DO ADOLESCENTE. Por que somos contrários à redução da maioridade penal?. Brasília: .CFP; CONANDA 2015. p. 178-187.

SPOSITO, M. P. Estudos sobre juventude em educação. Revista Brasileira de Educação, Rio de Janeiro, n. 5-6, p. 37-52, maio/dez. 1997. 
FabíOla Mônica da Silva Gonçalves: Possui graduação em Pedasogia pela Universidade Federal de Pernambuco, mestrado e doutorado em Psicologia Cognitiva pela Universidade Federal de Pernambuco. Atualmente é professora da Universidade Estadual da Paraíba. Tem experiência na área de Educação e de Psicologia, com atuação nos seguintes temas: processos humanos de desenvolvimento e aprendizagem; condições de produção de leitura, compreensão textual, formação do professor e medidas socioeducativas.

E-mail: francesfabiola@gmail.com 